\title{
Malate Accumulation in Different Organs of Mesembryanthemum crystallinum L. Following Age-dependent or Salinity-triggered CAM Metabolism
}

Marta Libik ${ }^{\mathrm{a}}$, Beata Pater $^{\mathrm{a}}$, Stewart Elliot ${ }^{\mathrm{b}}$, Ireneusz Ślesak ${ }^{\mathrm{a}}$, and Zbigniew Miszalski ${ }^{\mathrm{a}, \mathrm{c}, *}$

a Institute of Plant Physiology, Polish Academy of Sciences, ul. Niezapominajek 21, 30-239 Kraków, Poland. E-mail: miszalski@ifr-pan.krakow.pl

b Department of Agricultural and Environmental Science, University of Newcastle,

Newcastle upon Tyne NE1 7RU, United Kingdom

c Institute of Biology, Pedagogical Academy, ul. Podbrzezie 3, 31-054 Kraków, Poland

* Author for correspondence and reprint requests

Z. Naturforsch. 59c, 223-228 (2004); received July 4/September 26, 2003

Different organs of Mesembryanthemum crystallinum exhibit differing levels of CAM (Crassulacean acid metabolism), identifiable by quantification of nocturnal malate accumulation. Shoots and also basal parts of young leaves were observed to accumulate high concentrations of malate. It was typically found in mature leaves and especially prominent in plants subjected to salt stress. Small amount of nocturnal malate accumulation was found in roots of M. crystallinum plants following age-dependent or salinity-triggered CAM. This is an indication that malate can be also stored in non-photosynthetic tissue.

Measurements of catalase activity did not produce evidence of the correlation between activity of this enzyme and the level of malate accumulation in different organs of $M$. crystallinum although catalase activity also appeared to be dependent on the photoperiod. In all material collected at dusk catalase activity was greater than it was observed in the organs harvested at dawn.

Key words: Mesembryanthemum crystallinum, CAM, Catalase, Oxidative Stress

\section{Introduction}

Mesembryanthemum crystallinum in its native habitat (Namibian Desert of southern Africa) germinates in the short rainy season and changes its mode of photosynthesis from $\mathrm{C}_{3}$ to Crassulacean acid metabolism (CAM) in the dry season. Its further development is strictly influenced by progressive drought stress coupled with increasing salinity (Winter et al., 1978). Such conditions have resulted in the evolution of acclimatory processes which can be defined in terms of anatomical, phys-

Abbreviations: ABA, abscisic acid; AOS, active oxygen species; APX, ascorbate peroxidase (EC 1.11.1.11); BSA, bovine serum albumin; CAM, Crassulacean acid metabolism; CAT, catalase (EC 1.11.1.6); DDT, dithiothreitol; EDTA, ethylenediamine tetraacetic acid; GR, glutathion reductase (EC 1.11.1.9); NAD-ME, NADmalic enzyme (EC 1.1.1.38); NADP-ME, NADP-malic enzyme (EC 1.1.1.40); PAGE, polyacrylamide gel electrophoresis; PEPC, phosphoenolpyruvate carboxylase (EC 4.1.1.31); PEPCK, phosphoenolpyruvate carboxykinase (EC 4.1.1.32); Rubisco, ribulosebisphosphate carboxylase/oxygenase (EC 4.1.1.39); SOD, superoxide dismutase (EC 1.15.1.1); Tricine, $N$-tris(hydroxymethyl)methylglycine; Tris, tris(hydroxymethyl)aminomethane. iological, biochemical and molecular processes (Kluge and Ting, 1978; Lüttge, 1993; Adams et al., 1998).

CAM is a typical ecophysiological adaptation of plants to arid conditions (Lüttge, 1993; Grams and Thiel, 2002). Plants exhibiting CAM usually fix $\mathrm{CO}_{2}$ during the night with a concomitant synthesis of malic acid, which is stored in the vacuole. During daytime the accumulated malic acid is released and decarboxylated to provide $\mathrm{CO}_{2}$ for use via the Calvin cycle (Lüttge, 1993; Dodd et al., 2002). The CAM induction has been studied in considerable detail, but little is known about the common process induced from different stress factors that can stimulate CAM induction. In recent years $M$. crystallinum, a $\mathrm{C}_{3}$-CAM intermediate plant, has become a model for the investigation of involvement of stress factors including high salinity, osmotic stress, excess light and the exogenous application of $\mathrm{ABA}$ in $\mathrm{C}_{3} / \mathrm{CAM}$ transition (Chu et al., 1990; Taybi and Cushman, 1999; Ślesak et al., 2002). At the physiological level the consequence of these abiotic stresses have much in common. It seems that their common denominator could be a water 
stress component. Some molecular studies have shown that numerous stresses including osmotic stress, low temperature and exposure to ABA, can have a similar effect on the expression of CAM specific genes (Chu et al., 1990). Thus, it was possible to conclude that similar responses to differing environmental challenges could be due to the existence of a general plant response mechanism (Vernon et al., 1993).

In the laboratory conditions, CAM metabolism can be readily induced by irrigating plants with a solution containing $0.1-0.4 \mathrm{M} \mathrm{NaCl}$ (Cheng and Edwards, 1991). It is well documented that salt treatment apart from the osmotic stress, causes an increase of the level of active oxygen species (AOS) resulting in oxidative stress (Miszalski et al., 1998; Ślesak et al., 2003). In M. crystallinum and, similarly in other $\mathrm{C}_{3}$-CAM intermediate plants (e.g. Sedum album) the process of CAM induction (age-dependent or stress-triggered) is linked with the oxidative stress (Castillo, 1996; Miszalski et al., 1998).

Apart from its negative role AOS can function as secondary messenger in plants (Vranova et al., 2002). Generally, AOS are formed by partial reduction of molecular oxygen as a consequence of aerobic life. Because of the highly cytotoxic and reactive nature of AOS, their accumulation must be under tight control to prevent cellular damage. Plants posses a very efficient antioxidant system that helps to regulate the level of AOS (Foyer and Noctor, 2001; Vranova et al., 2002). During different biotic or abiotic stresses the balance between AOS and their scavengers is disturbed. High concentration of AOS can lead to cell death and induction of some genes whereas low concentration induces the expression of other genes and adaptive response dependently on the particular stimulus. Thus, besides the role in cellular damage, AOS are considered to act as ubiquitous signaling molecules in plants. To allow for this dual function, cellular level of AOS is controlled by some antioxidative enzymes for example SOD, CAT, APX (Castillo, 1996; Miszalski et al., 1998, Ślesak et al., 2002). There is a relationship between relative tolerance to oxidative stress and the capacity of organisms to increase their level of AOS scavengers (Bowler et al., 1992).

The CAM cycle displays a series of distinct features that occur at specific points during the circadian rhythm (Dodd et al., 2002). M. crystallinum, like other CAM plants, exhibits a diurnal pattern of expression and regulation of some enzymes engaged in carbon fixation (e.g. PEPC, PEPCK, Rubisco, NADP-ME and NAD-ME). From previous published works on $M$. crystallinum leaves it is known that also the activity of some antioxidative enzymes changes during the day (Niewiadomska et al., 1999; Miszalski et al., 2001). These oscillations can be regarded as an additional indicator of the functioning of CAM photosynthesis, however, the mechanisms of regulation of antioxidant enzymes are still poorly understood (Ślesak et al., 2002).

The changes in the morphology, anatomy, physiology, biochemistry and also molecular processes has been described previously for the life cycle of M. crystallinum (Baur et al., 1992; Cushman and Bohnert, 1997; Adams et al., 1998). However, it is not known if expression of CAM and oxidative stress linked with CAM induction is uniform throughout the plant. The aim of this experiment was to investigate the $\mathrm{C}_{3}$-CAM transition including the ability of the different parts of the plant to accumulate malate. This work also focused on the levels of CAT activity in different organs during CAM induction.

\section{Material and Methods}

\section{Plant material and culture conditions}

Plants of Mesembryanthemum crystallinum were grown from seeds in phytotron growth chambers in soil culture, under photoperiod $12 / 12 \mathrm{~h}$, temperature $25 / 17^{\circ} \mathrm{C}$ (day/night), $60 / 80 \%$ relative humidity, and irradiance of $250-300 \mu \mathrm{mol}$ quanta $\mathrm{m}^{-2} \mathrm{~s}^{-1}$ (PAR; $\lambda=400-700 \mathrm{~nm}$ ). Two types of plants were used for the experiment: 7 weeks-old plants irrigated with water (age-dependent CAM) and 7 weeks-old plants irrigated after 3 weeks with $0.4 \mathrm{M} \mathrm{NaCl}$ (salinity-triggered CAM). Plants were separated into different organs or their parts and they were frozen in liquid nitrogen to await further analysis:

- mature leaves (first and second leaf pair) separated into: apical part (Ml-Ap), basal part (Ml-Ba)

- mature leaves (first and second leaf pair) separated into: blade (Ml-Bl), rib (Ml-Ri)

- young leaves (third and fourth leaf pair) separated into: apical part (Yl-Ap), basal part (Yl$\mathrm{Ba})$

- shoots $(\mathrm{Sh})$

$-\operatorname{roots}(\mathrm{Rt})$. 


\section{Determination of malate concentration}

The differences in malate concentration ( $\Delta$-malate) at the beginning (6.00 a.m.) and at the end of the light period $(6.00$ p.m.) were measured in the cell sap of all samples as a basic indicator of CAM metabolism. For isolation of cell sap samples were frozen at $-22^{\circ} \mathrm{C}$, thawed and centrifuged for $3 \mathrm{~min}$ at $12000 \times \mathrm{g}$. The supernatant (cell sap) was used for determination of the malate concentration following the enzymatic method described by Möllering (1985).

\section{Protein determination}

To isolate fractions of soluble proteins, leaf material ( $1 \mathrm{~g}$ fresh weight) was homogenized at $4{ }^{\circ} \mathrm{C}$ using a pestle and mortar in $2.5 \mathrm{~cm}^{3}$ of extraction buffer (100 mm Tricine, adjusted with Tris to pH 8.0, containing $3 \mathrm{~mm} \mathrm{MgSO}_{4}, 1 \mathrm{~mm}$ DDT, $3 \mathrm{~mm}$ EDTA) at $4{ }^{\circ} \mathrm{C}$. Non-soluble material was removed by centrifugation for $1 \mathrm{~min}$ at $12000 \times g$.

Protein concentration was determined according to Bradford (1976), using the BioRad protein assay, with BSA as a standard. Soluble protein fractions were stored at $-40{ }^{\circ} \mathrm{C}$ until further use.

\section{Biochemical analysis of CAT}

The activity of CAT was measured spectrophotometrically, according to Aebi (1984), by monitoring the disappearance of $\mathrm{H}_{2} \mathrm{O}_{2}$ at $240 \mathrm{~nm}$, in $50 \mathrm{~mm}$ phosphate buffer, $\mathrm{pH} 7.0$, containing initially $13 \mathrm{~mm} \mathrm{H}_{2} \mathrm{O}_{2}$. Enzyme activity was defined as an amount of $\mathrm{H}_{2} \mathrm{O}_{2}$ [mmol] degraded by $1 \mathrm{mg}$ of protein during 1 minute.

\section{Results}

The level of nocturnal malate accumulation differed strongly throughout the whole plant (Table I). In salinity-triggered CAM plants the organs most active in diurnal malate accumulation were shoots $(15.9 \mathrm{~mm})$ and basal parts of young leaves (20.5 mM). In these plants malate was also accumulated in roots, reaching the level $1.8 \mathrm{~mm}$. In agedependent CAM plants the highest amount of malate was also observed in shoots $(8.0 \mathrm{~mm})$. However, similar to results obtained in young leaves of salinity-triggered plants, basal parts of the leaves accumulated more malate $(3.2 \mathrm{~mm})$ than apical parts $(1.0 \mathrm{~mm})$. In age-dependent CAM plants a small accumulation of malate was also found in roots $(0.1 \mathrm{~mm})$.
Table I. Diurnal oscillation of malate concentration $(\Delta-$ malate) [mM] in Mesembryanthemum crystallinum organs during age-dependent and salinity-triggered CAM $(n=3)$.

\begin{tabular}{llc}
\hline Samples & $\begin{array}{c}\text { Age-dependent } \\
\text { CAM }\end{array}$ & $\begin{array}{c}\text { Salinity-triggered } \\
\text { CAM }\end{array}$ \\
\hline Roots (Rt ) & $0.1 \pm 0.06$ & $1.8 \pm 0.09$ \\
Shoots (Sh) & $8.0^{*}$ & $15.9^{*}$ \\
$\begin{array}{l}\text { Mature leaves } \\
\text { Apical part (Ml-Ap) }\end{array}$ & $2.9^{*}$ & \\
Basal part (Ml-Ba) & $1.7^{*}$ & $12.3 \pm 0.02$ \\
$\begin{array}{l}\text { Mature leaves } \\
\text { Blade (Ml-Bl) }\end{array}$ & $3.0 \pm 0.09$ & $11.8^{*}$ \\
Rib (Ml-Ri) & $2.0^{*}$ & $12.7^{*}$ \\
Young leaves & & $11.0^{*}$ \\
Apical part (Yl-Ap) & $1.0^{*}$ & $13.0 \pm 0.07$ \\
Basal part (Yl-Ba) & $3.2^{*}$ & $20.5 \pm 0.02$ \\
\hline
\end{tabular}

* SD values were omitted when lower than 0.01 .
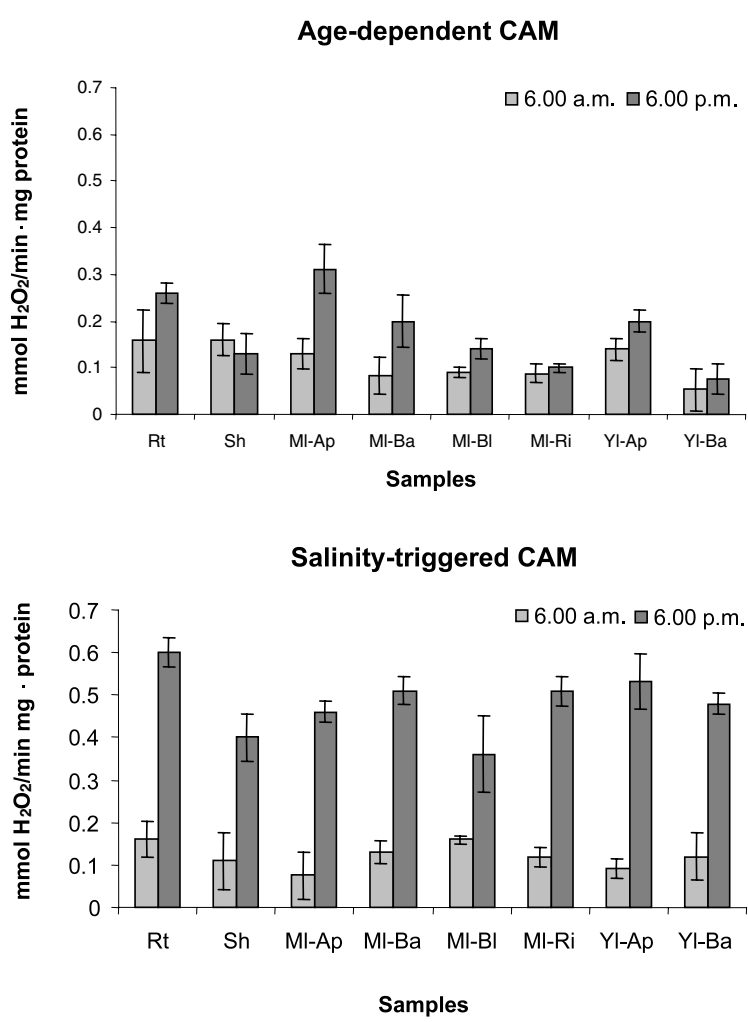

Fig. 1. CAT activity in different organs collected at 6.00 a.m. and 6.00 p.m. from age-dependent and salinity-triggered Mesembryanthemum crystallinum plants. 
In age-dependant CAM material, harvested at 6.00 a.m. CAT activity ranged in different parts of plant from 0.053 to $0.16 \mathrm{mmol} \mathrm{H}_{2} \mathrm{O}_{2} / \mathrm{min} / \mathrm{mg}$ protein and in plants harvested at 6.00 p.m. from 0.076 to $0.31 \mathrm{mmol} \mathrm{H}_{2} \mathrm{O}_{2} / \mathrm{min} \mathrm{mg}$ protein (Fig. 1). In the salinity-triggered CAM plants harvested at 6.00 a.m. the CAT activity ranged from 0.075 to $0.16 \mathrm{mmol} \mathrm{H}_{2} \mathrm{O}_{2} / \mathrm{min} / \mathrm{mg}$ protein (Fig. 1). A low level of CAT activity in salinity-triggered CAM plants collected at 6 a.m. is not sufficient to be detectable on the native activity stained gels in contrast to the CAT activity in the salt treated material harvested at 6.00 p.m., where it oscillated between 0.36 to $0.6 \mathrm{mmol} \mathrm{H}_{2} \mathrm{O}_{2} / \mathrm{min} / \mathrm{mg}$ protein (Fig. 1) which was visible on native gels (data not shown).

\section{Discussion}

Measurements of differences in malate concentration between morning and evening hours $(\Delta-$ malate) presented in this paper confirmed previous findings that salt applied to the root medium can stimulate the development of CAM in M. crystallinum (Lüttge, 1993; Cushman and Bohnert, 1997; Adams et al., 1998). In $\mathrm{NaCl}$ treated material (salinity-triggered CAM plants) large amounts of malate stored during the night were measured. Also in the plant tissues not treated with $\mathrm{NaCl}$ (age-dependent CAM plants) accumulation of malate was shown, suggesting that CAM metabolism was also induced.

Day/night malate oscillations were also detectable in shoots of both age-dependent CAM and salinity-triggered CAM plants. It indicates that shoot tissues are also capable of CAM mode of photosynthesis. This result corresponds with results observed in many other succulent plants, for example cactus where CAM is performed just in shoots (Winter and Smith, 1996).

Using malate accumulation as an indicator it was observed that CAM is not induced with the same intensity in different organs of $M$. crystallinum (Table I). Similarly in the dicotyledonous tree Clusia minor it has been demonstrated that CAM can be induced only in the leaves exposed to the stress regime (dry air or high light) while the other leaves continue to show $\mathrm{C}_{3}$ metabolism (Dodd et al., 2002; Grams and Thiel, 2002).

Different parts of $M$. crystallinum leaves showed only small differences in malate concentration. In young leaves, the concentration of malate was higher in the basal part of the leaf than in the apical part in contrast to old leaves where these values were reverse (Table I). Those differences can be due to the process of leaf growth and development. Older leaves had their blades in the apical part well unfolded and exposed to high light, while young leaves had their blades still partially folded. It has been already established that to evolve day/ night differences in malate concentration high light as well as salinity is required because it stimulates some CAM related enzymes (Miszalski et al., 2001). In young leaves higher concentration of malate in the basal region may result only from influence of the salt presence transported from the roots.

Detectable amounts of $\Delta$-malate was observed in roots of plants exposed to salinity stress (Table I). This is evidence that malate can be also stored in non-photosynthetic cells. The possibility of malate storage in non-photosynthethic tissues was mentioned by Holtum (2001).

However, we do not know if malate is synthesized in these tissues or transported there from other organs. This information together with the observation that shoot tissue is very active in malate accumulation might indicate that salt or other signals coming from roots can effectively induce CAM. Malate is involved in different pathways depending on plant organs. Malate can function as an intermediate in Krebs-cycle, as an osmoticum for the regulation of $\mathrm{pH}$ and transport ions in the roots (Casati et al., 1999). In our experiments the high volume accumulated periodically during the dark period indicates that its main role is to store carbon for later breakdown and use $\mathrm{CO}_{2}$ in the Calvin cycle.

CAT activity present in the cells of different parts of the plants growing in different conditions was measured by spectrophotometric analysis and visualized by CAT activity staining on native gels (data not shown). As it is known that catalase shows diurnal fluctuation of the activity (Niewiadomska et al., 1999) therefore, the extracts were prepared from plants collected at the beginning of the light period (6.00 a.m.) and at the end of the light period (6.00 p.m.). CAT activity in age-dependent CAM plants (low malate accumulation) showed in most samples small increase in activity during afternoon. This result is similar to measurements of CAT activity in well-watered plants (not treated with salt) presented by Niewiadomska et al. (1999). Much higher CAT activity mainly in 
salinity-triggered CAM plants in samples collected at $6.00 \mathrm{p} . \mathrm{m}$. can be explained in terms of the age of plants used in this experiment. They could exhibit processes of senescence.

It is prominent that in root samples, non-photosynthetic tissue, this photorespiratory enzyme showed high activity (Fig. 1). This was also confirmed in native-PAGE experiments (data not shown). In salt-triggered CAM, CAT activity in all tested samples was higher in plant material harvested during the afternoon (Fig. 1B). A similar result was also observed in experiments with root extracts where CAT activity was higher than observed in leaf extracts. This indicates that catalase, a photosensitive enzyme, is protected in root tissues (Streb et al., 1998). Strong day/night oscilla-

Adams P., Nelson D., Yamada S., Chmara W., Jensen R., Bohnert H., and Griffiths H. (1998), Growth and development of Mesembryanthemum crystallinum (Aizoaceae). New Phytol. 138, 171-190.

Aebi H. (1984), Catalase in vitro. Meth. Enzymol. 105, $121-126$.

Baur B., Dietz K.-J., and Winter K. (1992), Regulatory protein phosphorylation of phosphoenolpyruvate carboxylase in the facultative Crassulacean-acid plant Mesembryanthemum crystallinum. Eur. J. Biochem. 209, 95-101.

Beauchamp C. and Fridovich I. (1971), Superoxide dismutase: improved assays and an assay applicable to acrylamide gels. Anal. Biochem. 44, 276-287.

Bradford M. M. (1976), A rapid and sensitive method for quantification of microgram quantities of protein utilizing the principle of protein-dye binding. Anal. Biochem. 72, 248-254.

Bowler C., Van Montagu M., and Inzé D. (1992), Superoxide dismutase and stress tolerance. Ann. Rev. Plant Physiol. Plant Mol. Biol. 43, 83-116.

Casati P., Dricovich M. F., Edwards G. E., and Andreo C. S. (1999), Malate metabolism by NADP-malic enzyme in plant defense. Photosynth. Res. 61, 99-105.

Castillo F. (1996), Antioxidative protection in the inducible CAM plant Sedum album L. following the imposition of severe water stress and recovery. Oecologia 107, 469-477.

Cheng S.-H. and Edwards G. E. (1991), Induction of Crassulacean acid metabolism in the facultative halophyte Mesembryanthemum crystallinum. Plant Cell Environ. 14, 271-278.

Chu C., Dai Z., Ku M. S. B., and Edwards G. (1990), Induction of Crassulacean acid metabolism in the facultative halophyte Mesembryanthemum crystallinum by abscisic acid. Plant Physiol. 93, 1253-1260.

Cushman J. and Bohnert H. (1997), Molecular genetics of Crassulacean acid metabolism. Plant Physiol. 113, $667-676$.

Dodd A., Borland A., Haslam R., Griffiths H., and Maxwell K. (2002), Crassulacean acid metabolism: plastic, fantastic. J. Exp. Bot. 53, 569-580. tion in activity of CAT in root extracts suggests that this enzyme is involved in CAM and even in the roots CAT activity can protect against oxidative stress. If this assumption is correct, then it might indicate that in $M$. crystallinum some photorespiratory processes can take place also in nonphotosynthetic tissue.

\section{Acknowledgements}

We would like to thank Dr Ewa Niewiadomska (Kraków, Poland) for critical reading of the manuscript. This work was partly supported by the Polish KBN grants: 6P04C 00320, 6P04F 03420 and 3P04C06423. The Deutsche Akademische Austauschdienst (DAAD) has provided the growth chambers.

Foyer C. H. and Noctor G. (2001), Oxygen processing in photosynthesis: regulation and signalling. New Phytol. 146, 359-388.

Grams T. and Thiel S. (2002), High light-induced switch from $\mathrm{C}_{3}$-photosynthesis to Crassulacean acid metabolism is mediated by UV-A/blue light. J. Exp. Bot. 53, $1475-1483$.

Holtum J. A. M. (2001), Proceed. $3^{\text {rd }}$ Intern. Congr. Crassulacean Acid Metabolism (James Cook University School of Tropical Biology, Townsville, Australia, ed.). CSIRO Publishing, Collingwood.

Kluge M. and Ting I. P. (1978), Crassulacean Acid Metabolism. Analysis of an Ecological Adaptation (Kluge M. and Ting I. P., eds.). Springer, Berlin, Heidelberg, New York.

Lüttge U. (1993), The role of crassulacean acid metabolism (CAM) in the adaptation of plants to salinity. New Phytol. 125, 59-71.

Miszalski Z., Ślesak I., Niewiadomska E., BączekKwinta R., Lüttge U., and Ratajczak R. (1998), Subcellular localization and stress responses of superoxide dismutase isoforms from leaves in the $\mathrm{C}_{3}$-CAM intermediate halophyte Mesembryanthemum crystallinum L. Plant Cell Environ. 21, 169-179.

Miszalski Z., Niewiadomska E., Ślesak I., Lüttge U., Kluge M., and Ratajczak R. (2001), The effect of irradiance on carboxylating/decarboxylating enzymes and fumarase activities in Mesembryanthemum crystallinum L. exposed to salinity stress. Plant Biol. 3, $17-23$.

Möllering H. (1985), Malate. In: Methods of Enzymatic Analysis (Bergmeyer H. U., ed.). VCH Verlagsgesellschaft, Weinheim, pp. 39-47.

Niewiadomska E., Miszalski Z., Ślesak I., and Ratajczak R. (1999), Catalase activity during $C_{3}$-CAM transition in Mesembryanthemum crystallinum. Free Rad. Res. 31, S51-S56.

Ślesak I., Miszalski Z., Karpińska B., Niewiadomska E., Ratajczak R., and Karpiński S. (2002), Redox control of oxidative stress responses in the $\mathrm{C}_{3}$-CAM intermediate plant Mesembryanthemum crystallinum. Plant Physiol. Biochem. 40, 669-677. 
Ślesak I., Karpińska B., Surówka E., Miszalski Z., and Karpiński S. (2003), Redox changes on chloroplast and hydrogen peroxide are essential for regulation of $\mathrm{C}_{3}$-CAM transition and photooxidative stress responses in the facultative CAM plant Mesembryanthemum cystallinum L. Plant Cell Physiol. 44, 573-581.

Streb P., Shang W., and Feierabend J. (1998), Divergent strategies of photoprotection in high-mountain plants. Planta 207, 313-324.

Taybi T. and Cushman J. (1999), Signaling events leading to Crassulacean acid metabolism induction in the common ice plant. Plant Physiol. 121, 545-555.

Vernon D., Ostrem J., and Bohnert H. (1993), Stress perception and response in a facultative halophyte: the regulation of salinity-induced genes in Mesembryanthemum crystallinum. Plant Cell Environ. 16, 437-444. Vranova E., Inzé D., and Breusegem F. (2002), Signal transduction during oxidative stress. J. Exp. Bot. 53, $1227-1236$.

Winter K., Lüttge U., Winter E., and Troughton J. H. (1978), Seasonal shift from $\mathrm{C}_{3}$ photosynthesis to Crassulacean acid metabolism in Mesembryanthemum crystallinum growing in its natural environment. Oecologia 34, 225-237.

Winter K., and Smith J. A. C. (1996), Crassulacean Acid Metabolism. Biochemistry, Ecophysiology and Evolution (Lange O. L. and Mooney H. A., eds.). Springer, Berlin, Heidelberg, New York, pp. 400. 